Total-Task Presentation as a Technique to Develop Self-Drinking Skill: A Single-Case Study of an Autistic Child with Intellectual Impairment

Yasmine Nur Edwina $^{\mathrm{a}}$ and Mita Aswanti Tjakrawiralaksana ${ }^{\mathrm{b} *}$

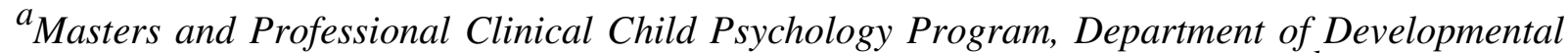
Psychology, Faculty of Psychology, Universitas Indonesia, Depok, Indonesia; ${ }^{b}$ Department of Developmental Psychology, Faculty of Psychology, Universitas Indonesia, Depok, Indonesia

*Corresponding Author:

Mita Aswanti Tjakrawiralaksana

Developmental Psychology Department

Faculty of Psychology, Universitas Indonesia

Jl. Lkr. Kampus Raya, Depok, Jawa Barat

Indonesia, 16424

Tel.: +62 217270004

email address: mita.aswanti@ui.ac.id 


\title{
Total-Task Presentation as a Technique to Develop Self-Drinking Skill: A Single-Case Study of an Autistic Child with Intellectual Impairment
}

\begin{abstract}
Using a pre-post intervention design, this study aims to evaluate the use of total-task presentation technique in a training program to develop the self-drinking skill of a 9-yearold male child who features autism spectrum disorder (ASD) with intellectual impairment. This study consists of three phases, including baseline, intervention, and follow-up phase. The baseline phase consists of six trials in two days. The intervention program consisted of five trials on each session and was conducted every lunchtime for 45-60 min. The intervention program involved six stages and was completed in seven days at the subject's home. Thus, in total, the intervention program consisted of 35 trials in seven days. Follow-up data were obtained one and two weeks after concluding the intervention program. The follow-up consisted of six trials in two days. To examine the program's effectiveness, baseline and follow-up results were compared using four features of visual analysis. Results showed the increase in behavior mastered in the chain of behavior. The subject performed 20 out of 21 steps of the behavior in the follow-up phase without any prompts and could perform 6 in the baseline phase. In this case, results indicate that total-task presentation technique can improve mastery of self-drinking skill of a child with ASD with intellectual impairment.
\end{abstract}

Keywords: autism spectrum disorder; behavior modification; pre-post intervention evaluation; self-drinking; total-task presentation

\section{Introduction}

In general, children with autism spectrum disorder (ASD) experience deficits in social and practical skills related to daily living functions. Their limited two-way communication skills primarily hinder children with ASD from learning daily living skills. Limitations in performing joint attention and imitation cause children with ASD difficulties in learning daily living skills from their environment (Thurms, Lord, Lee, \& Newschaffer, 2007; Vivanti, Barbaro, Hudry, Dissanayake, \& Prior, 2013). Repetitive or stereotypical behavior that are often exhibited by children with ASD can disrupt everyday activities insofar that they require adult supervision to help them resume to their activities. Results of a study showed that more serious ASD results in a more significant deficit in mastery of useful daily living skills (Perry, Flanagan, Geier, \& Freeman, 2009).

Skills that benefit everyday routines, also called self-care or self-help skills, include skills related to eating, drinking, and cleaning of one's self (showering, urinating, defecating, and dressing). Self-drinking is one of the self-help skills typically mastered by young children. In general, children can drink by themselves from an open cup starting at the age of three (Carruth \& Skinner, 2002). This skill is important for children's autonomy and nutrition. However, children with ASD possess limitations that often hinder them from mastering such skills at a later developmental stage. Flyn and Healy (2012) stated that mastery of daily living skills, with one of them being the ability to drink and acquire one's own drink, is crucial for individuals with ASD to allow them to live a more autonomous life in the community.

A review by Wong et al. (2015) showed that behavior modification intervention can help 
children with ASD to improve their self-help skills. The principles used in behavior modification intervention, such as reinforcement and others, have been scientifically proven to be effective in improving self-help skills of individuals with ASD from preschool (0-2 years) to young adulthood (19-22 years) (Wong, et al., 2015). Mastery of self-help skills can be used to train children with ASD by using teaching methods that break down activities into small steps and systematically use instructions in the process (Anderson, Jablonski, Thomeer, \& Knapp, 2007), which includes task analysis and chaining. Task analysis is used to analyze the behavioral chain of a skill or behavior and breaks it down into small parts of a stimulus-response (Martin \& Pear, 2015). According to Martin and Pear (2015), chaining is a technique for teaching a series of behavior, which is broken down into stimulus-response by implementing the prompt and fading procedure. One of the chaining techniques, total-task presentation, is effective for developing self-help skills in a short period of time (Martin \& Pear 2015). Results of a study showed that total-task presentation technique is effective for training behavioral chains related to more complex academic skills to children with intellectual disability (Jameson, Walker, Utley, \& Maughan, 2012).

However, several studies only evaluated the application of total-task presentation technique on improving daily living and academic skills in children with intellectual disability (Jameson et al., 2012; Spooner, 1984). Several studies examined the effectiveness of teaching programs but only for drinking skill and not the series of skills including taking the cup and placing it back to its original spot. On the other hand, a case of a child with ASD with intellectual impairment presented low mastery of self-drinking skill. The child requires further training to help him master self-drinking skills, starting from picking up bottles and glasses and putting them back to their original place. Based on these considerations, this study aims to investigate the effectiveness of total-task presentation technique in a program that teaches a child with ASD with intellectual impairment how to drink independently.

\section{Methods}

\section{Participant}

The participant of this study is $\mathrm{R}$ (initial of the name), a boy aged 9 years and 2 months and who has been diagnosed with ASD with intellectual impairment (requiring substantial support for communication and support for repetitive and restricted interest). The patient is a client at Klinik Terpadu Fakultas Psikologi, Universitas Indonesia. At the time of intervention, the patient was starting to maintain eye contact with others for 10-15 s. When his name is called, the patient can turn his head to the source of the voice. $\mathrm{R}$ can also understand verbal instructions consisting of one to two words, especially if the instruction is delivered consistently for a specific activity. Repetitive behavior, which include clapping loudly and knocking on objects, often disrupt his everyday activities. In such case, the mother of the patient directs him to resume to the activities at hand. However, using physical contact prompts to redirect the patient cause's difficulty as $\mathrm{R}$ is sensitive to touch.

Based on the developmental checklist and clinical judgments, R's developmental aspects that are related to his intellectual function equal those of a 1- or 2-year-old child. The deficit in intellectual function correlates to the decrease in adaptive function, especially regarding R's selfhelp skills. R needs help from his mother to perform most daily activities. Thus, his self-help 
skills equal those of a 1-year-old. Regarding R's self-drinking skill, prior to the intervention program, $\mathrm{R}$ was extremely reliant on his mother for picking up his drink for him. According to the mother, $\mathrm{R}$ was starting to become familiar with the first few steps of self-drinking, but she has not consistently taught the skill because $\mathrm{R}$ often rejects the invitation by throwing a fit. Considering his level of soft motor skills, R's ability can support him in taking his own drink because he can open doors and hold a bottle or glass. R predominantly uses his left hand.

\section{Research Design}

The current study is a single-case study which uses a pre-post intervention evaluation design. Behavioral measures were obtained before (baseline phase), throughout (intervention phase), and after the intervention (follow-up phase). The whole program was carried out in 10 days: 2 days for the baseline phase, 6 days for the intervention phase, and 3 days for the follow-up phase. The duration of each session per day was 45-60 min, with three trials per session for the baseline and follow-up phase and five trials per session for the intervention phase. Results of the baseline phase served as control, and they were compared with the findings of the follow-up phase.

The behavior modification intervention program implemented on $\mathrm{R}$ is a form of clinical care. However, R's parents still had to sign an informed consent to be a part of the program and research project. The parents signed and were given a copy of the informed consent before initial assessment.

\section{Measures}

Self-drinking behavior is the target behavior of this behavior modification intervention program. The operational definition of self-drinking behavior is walking toward the location of the water bottle and glasses, picking up a glass, picking up the bottle, pouring water into the glass up to the mark, drinking from the glass, and placing the bottle and glass back to their original position.

The measurement method used is observation. Table 1 shows the observation sheet used in each phase to observe self-drinking behavior. The observation sheet was developed based on the results of a task analysis carried out by the author.

Table 1

Example of Self-Drinking Behavior Observation Sheet

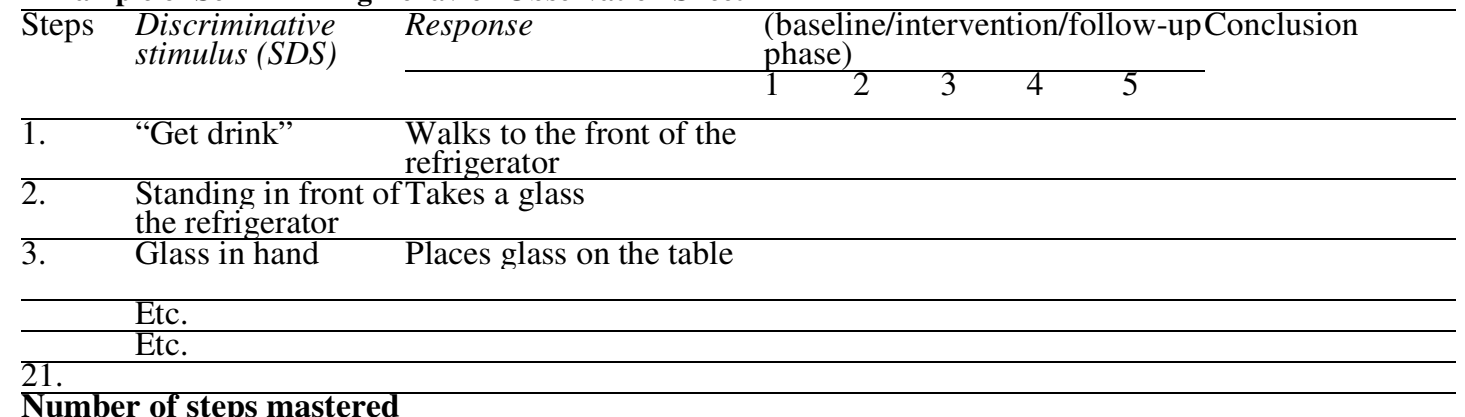

Number of steps mastered

On the observation sheet, the observer can record the prompts needed by the participant in each trial. Scores between $0-4$ can be given according to the prompts given on each step. The guide to 
the scoring system is as follows: 4 (without prompt), 3 (verbal prompt), 2 (gestural prompt with verbal prompt), 1 (full physical prompt with verbal prompt), and 0 (stage not performed and completed by another person). In giving scores regarding the prompts used for each step, the most intrusive prompt is recorded. For instance, if gestural prompt was initially given, but full physical prompt was later given to help $\mathrm{R}$ complete the step, then the score given should be 1 because the prompt which helped him perform the task is a full physical prompt.

Based on observation sheet, the number of steps mastered by the participant can be obtained. Mastery of behavior is indicated by the step which receives a score of 4 . The participant can be said to have mastered a step if he receives a score of 4 in three of the five trials. The observation sheet will also be able to record and show the prompts needed by the participant to complete each step. This is indicated by the consistency of the prompt needed by the participant. Then, the observation sheet will be used to determine which prompt should be used to help $\mathrm{R}$ in the next session in intervention phase.

Continuous recording is used as data collection method. In this method, the observer observes for a set period of time and records the presence of the target behavior throughout (Martin \& Pear, 2015). The continuous recording method was selected given the lack of specific duration and time when the target behavior is present. However, one of the few times when the target behavior is present was during lunch time (between 12.00 PM-01.00 PM). Therefore, each step of the behavior was measured during lunch time. The dimension of the behavior measured, which is the presence of self-drinking behavior in $\mathrm{R}$, is frequency.

During the baseline phase, the behavior was measured six times ( 2 sessions, with 3 trials per session). In the intervention phase, the behavior was measured 30 times ( 6 sessions, with 5 trials per session). In the follow-up phase, the behavior was measured six times ( 2 sessions, with 3 trials per session). The number of times the behavior was measured during the intervention phase was adjusted to the participant's level of success in each session. If the participant failed to reach the target on a certain stage, additional sessions were conducted, and the amount of time the behavior was measured was increased.

\section{Procedure}

In the current study, the entire research process was conducted by the author as a student in the Master's and Professional Clinical Child Psychology program, in Universitas Indonesia, under the supervision of lecturers who are experts in the field of developmental psychology and of licensed psychologists certified by the Indonesian Psychological Association (Himpunan Psikologi Indonesia). The author was also the program designer, observer, and implementer of the program. In the intervention phase, the participant's mother also acted as an observer. However, in R's case, the mother distracted R because she simultaneously gave instructions with the author. Given this situation, the author, as a program implementer, also acted as observer and recorded results of each session.

The intervention program began with conducting a functional behavior assessment to identify the function of behavior and to identify the correlation between antecedent, behavior, and consequences. An effective behavior modification program was then constructed. 
Table 2

Functional Behavior Assessment of Self-Drinking Behavior

\begin{tabular}{|c|c|c|}
\hline Antecedent & Behavior & Consequence \\
\hline Feeling thirsty; asks for a drink & Does not drink on his own & Mother, father, or sibling helps to \\
\hline Not able to drink independently & & get the drink for $\mathrm{R}$ so $\mathrm{R}$ becomes \\
\hline $\begin{array}{l}\text { Parents have not consistently } \\
\text { trained R to drink independently }\end{array}$ & & dependent on other people \\
\hline
\end{tabular}

Table 2 shows the results of functional behavior assessment. According to results, $\mathrm{R}$ does not drink on his own as his family constantly help him and do not teach him the drinking skill. This condition makes him dependent on his family. To make him become independent and able to drink by himself, the program designer planned to develop self-drinking behavior. Following functional behavior assessment, a task analysis assessment of self-drinking behavior was conducted by interviewing the mother and observing the natural occurrence of the behavior at R's home. The results of task analysis include a behavioral chain of the target behavior (Martin $\&$ Pear, 2015). Table 3 shows the behavioral chain of self-drinking behavior at R's home obtained based on task analysis.

Table 3

Task Analysis of Self-Drinking Behavior

\begin{tabular}{cll}
\hline $\begin{array}{c}\text { Steps of } \\
\text { implementation }\end{array}$ & \multicolumn{1}{c}{ Discriminative stimulus } & Responses \\
\hline 1 & "Let's drink" & Walks toward the refrigerator \\
\hline 2 & Stands in front of the refrigerator & Picks up the glass \\
\hline 3 & Glass in hand & Places glass on the table \\
\hline 4 & Glass on the table & Walks toward the refrigerator \\
\hline 5 & Stands in front of the refrigerator & Opens refrigerator door \\
\hline 7 & Refrigerator opened & Takes the bottle of water \\
\hline 8 & Bottle of water in hand & Closes refrigerator door \\
\hline 9 & Refrigerator closed and bottle of water in & Walks toward the table, stands facing the glass, holds the \\
hand & $\begin{array}{l}\text { Stands in front of the glass while holding } \\
\text { bottle of water with both hands }\end{array}$ & Pours water out of the bottle into the glass until the mark \\
\hline 10 & Glass filled with water & Places the bottle on the table again and picks up the glass \\
\hline 11 & Holds glass & $\begin{array}{l}\text { Directs the glass toward the mouth and drinks out of the } \\
\text { glass }\end{array}$ \\
\hline 12 & Finished drinking & Places glass on the table \\
\hline 13 & Glass is on the table & Picks up the bottle of water \\
\hline 14 & Bottle of water in hand & Walks toward the refrigerator \\
\hline 15 & Stands in front of the refrigerator & Opens the refrigerator \\
\hline 16 & Refrigerator opened & Places the bottle inside of the refrigerator \\
\hline 17 & Bottle is inside of the refrigerator & Closes refrigerator door \\
\hline 18 & Refrigerator door closed & Walks toward the glass on the table \\
\hline 19 & Stands in front of the glass & Picks up the glass \\
\hline 20 & Glass in hand & Walks toward the refrigerator \\
\hline 21 & Stands in front of the refrigerator & Places the glass on top of the refrigerator \\
\hline
\end{tabular}

The whole program took place at R's home at lunch time, from 11.30 AM to 12.30 PM. The equipment used included a glass, a bottle of water, the refrigerator, and the table. The glass used was always positioned on top of the refrigerator; the bottle of water was in the refrigerator and 
with the lid open to allow R to easily pour water into the glass. Near the refrigerator was a table where the glass was placed, and water was poured into the glass.

Baseline. The baseline phase was carried out over two consecutive days. In this phase, the observer noted for the natural occurrence of self-drinking behavior. The observer did not interrupt and let $\mathrm{R}$ perform the behavior with the help of people around him, namely, his mother and 4-year-old sibling. A reinforcer assessment was also conducted by interviewing I's mother. Based on the interview, two reinforcers were used during intervention: 1) social reinforcers in the form of praises, such as "You are great!" and "Yay, you can do it!" along with applauses, and 2) consumable reinforcer in the form of small cracker pieces.

Intervention. Following the baseline phase, $\mathrm{R}$ began the six-stage intervention phase. Each session focused on one stage and consisted of five trials. A stage can be considered successful if $\mathrm{R}$ can accomplish the target of that stage. Sessions will be repeated if $\mathrm{R}$ fails to meet the success criteria of a stage. Sessions were scheduled for six consecutive days, with 45-60 min per session during lunch time (11.30 AM-12.30 PM). However, the sessions were not carried out consecutively due to the health condition of R's mother. Another session was also added at the end because $\mathrm{R}$ could not accomplish the target of the sixth stage in one session.

Total-task presentation technique was the main technique used in the program to teach $\mathrm{R}$ how to perform self-drinking. With this technique, all steps of the behavior were taught. In using totaltask presentation technique, prompts are given with each step taught (Martin \& Pear, 2015). The prompting techniques used in this intervention comprised full physical prompts paired with verbal prompts, gestural prompts paired with verbal prompts, and verbal prompts alone. The prompts were given using the most-to-least prompting and fading method, where prompts started with the most intrusive ones (full physical prompt) and gradually decreased to the least intrusive ones (verbal prompts). When R performed the steps without prompting, the prompts were slowly ceased (fading). Social reinforcer was given every time $\mathrm{R}$ successfully performed the targeted steps of a behavior, whereas social and consumable reinforcers were provided simultaneously every time R successfully completed the chain of behavior with or without any help.

On each session, the intervention program started during R's lunch. Throughout his lunch time, if $\mathrm{R}$ declined to drink at all, the author, as the program implementer, would instruct $\mathrm{R}$ to drink by saying, "Let's drink." If R showed desire to drink, the instruction will be repeated. To ensure that $\mathrm{R}$ can perform all the steps on the chain of behavior of self-drinking, the program implementer will empty the water from R's glass at the end of every trial.

Follow up. To determine the success of intervention, a follow-up was conducted twice after the end of the behavior modification program. The first follow-up session was conducted one week after the end of the intervention phase and the second, two weeks after the intervention phase. These follow-up sessions were performed to identify the response maintenance after the program. To determine and evaluate the success of total-task presentation technique on the behavior modification program, mastery of the chain of behavior of self-drinking in the baseline phase was compared with that during the follow-up phase.

\section{Data Analysis}

A visual analysis was carried out to analyze data. Four features were used to examine the effectiveness of the intervention conducted: 1) level within phase, 2) trend within phase, 3) 
immediacy effect between phases, and 4) overlap effect between different phases. Consistency between these data will provide evidence for this study. Based on the work of Kratochwill et al. (2010), level refers to the mean score of all data in one phase. Trend is the slope of the bestfitting straight line for data within a phase. Immediacy effect of an intervention can be measured by changes in levels between the last three data points in one phase and the first three data points of the next. The overlap effect can be identified from the data proportion that overlaps between the data on one phase and another phase. The level and trend of every phase must be identified to describe a performance. On the other hand, the swift change between phases can solidify the effectiveness of intervention. Small data overlap between phases also signifies the large effect of intervention (Kratochwill, et al., 2010).

\section{Results}

$\mathrm{R}$ completed seven sessions of the behavior program which taught self-drinking behavior in seven days. With two interruptions, $\mathrm{R}$ failed to complete the program in seven consecutive days. The first interruption, which was the mother's health condition, lasted three days and occurred after the third session. The second interruption lasted one day due to the same reason and transpired after the fifth session.

Figure 1 shows R's progress in mastering the steps of self-drinking behavior, from the baseline to the follow-up phase with a total of 47 trials, as shown in the visual analysis with the level feature. Improvement of mastery level can be observed by comparing the baseline and follow-up levels. In the baseline level, mastery level is 6. Mastery level improved to 20 in the follow-up phase. This finding implies that $\mathrm{R}$ can consistently perform self-drinking behavior or drink independently.

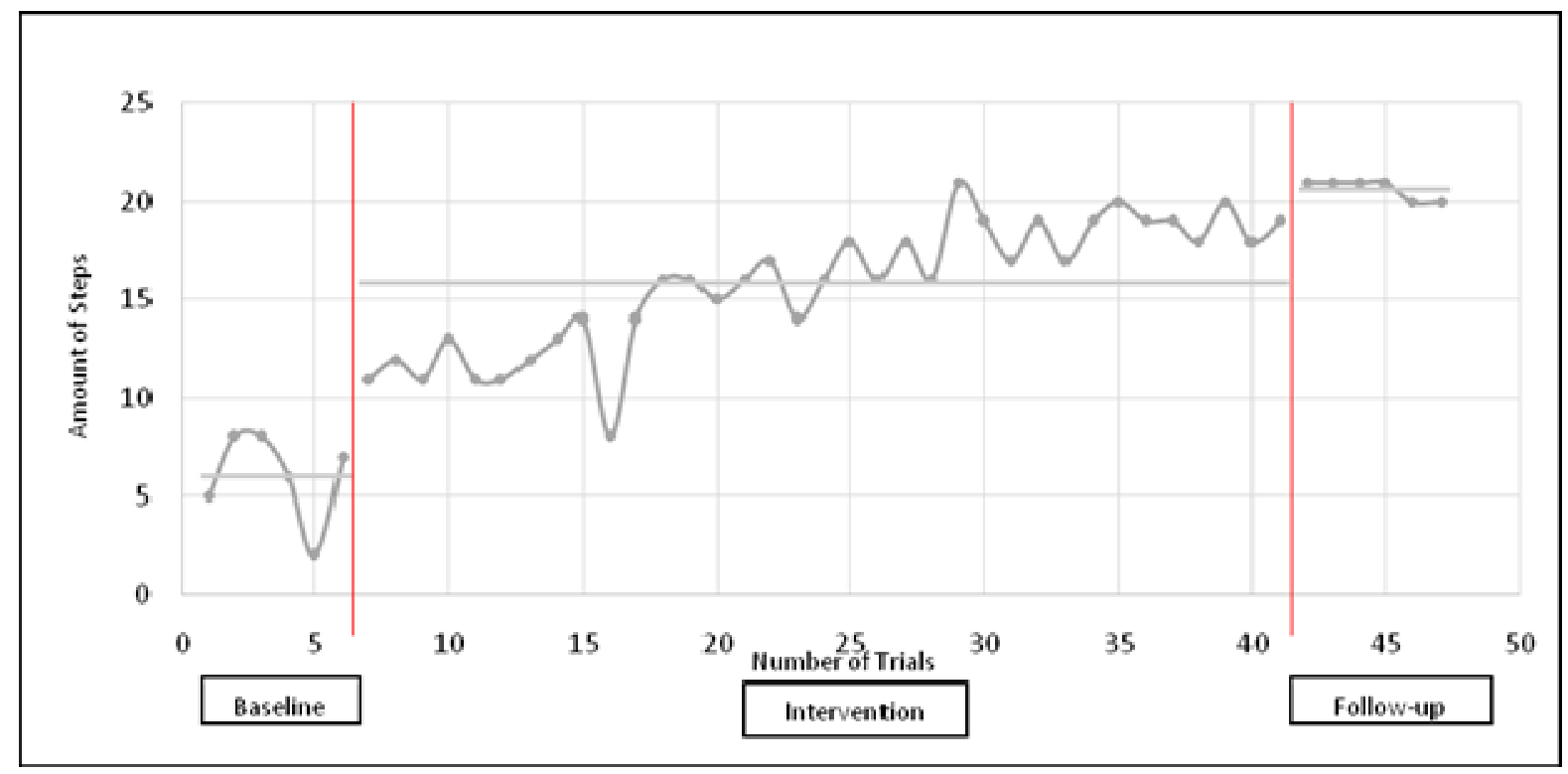

Figure 1. Level of Self-Drinking Skill Mastery

Figure 2 shows results of visual analysis performed by measuring the trend of each phase. Improvement of mastery of behavior is indicated by the trend of each phase. The most prominent 
improvement occurred during the intervention phase. This result implies that the intervention program can improve mastery of self-drinking behavior.

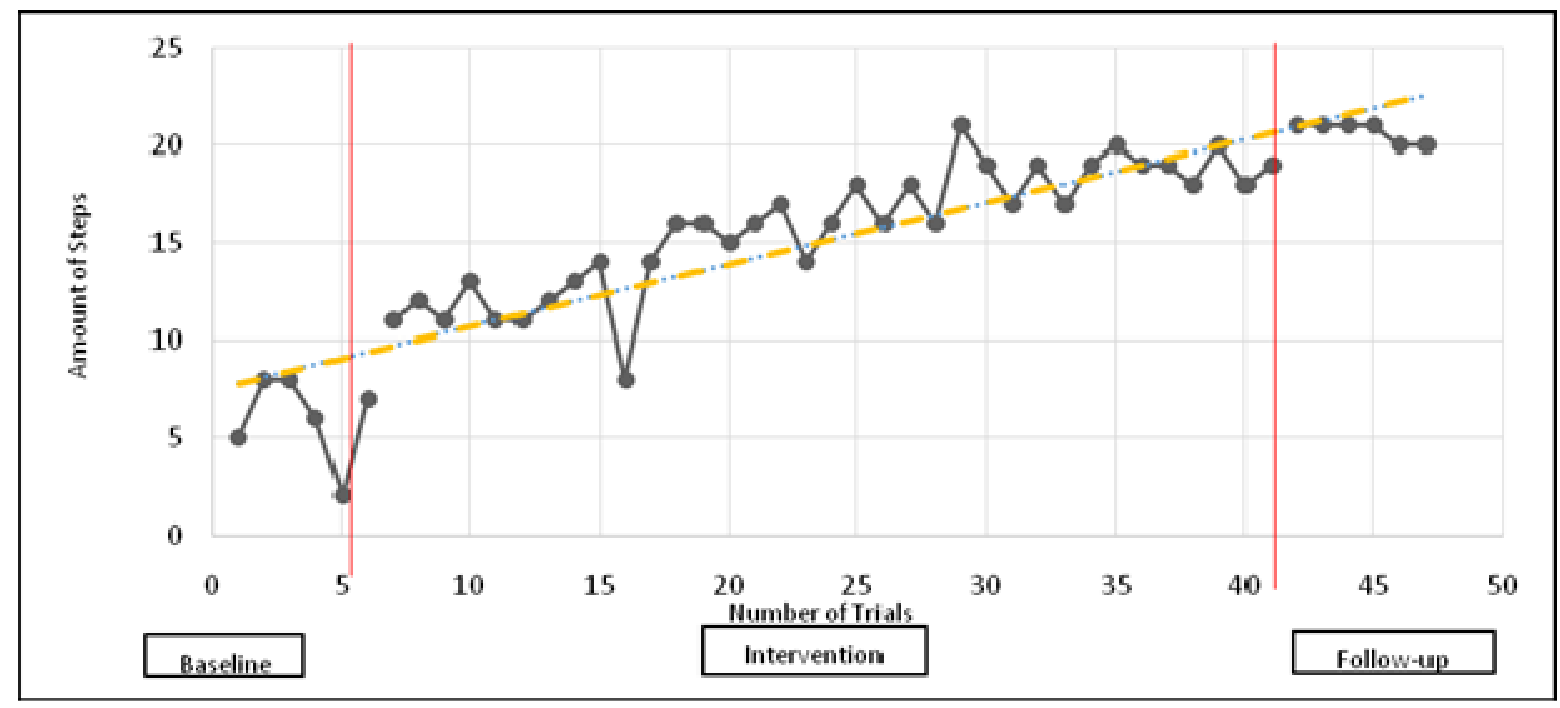

Figure 2. Trend of Self-Drinking Skill Mastery

In Figure 3, the data marked with ovals and squares show the immediacy of the effect in visual analysis. A swift change occurred between the baseline and intervention phases. This result indicates that the improvement during intervention resulted from the implementation of the intervention program.

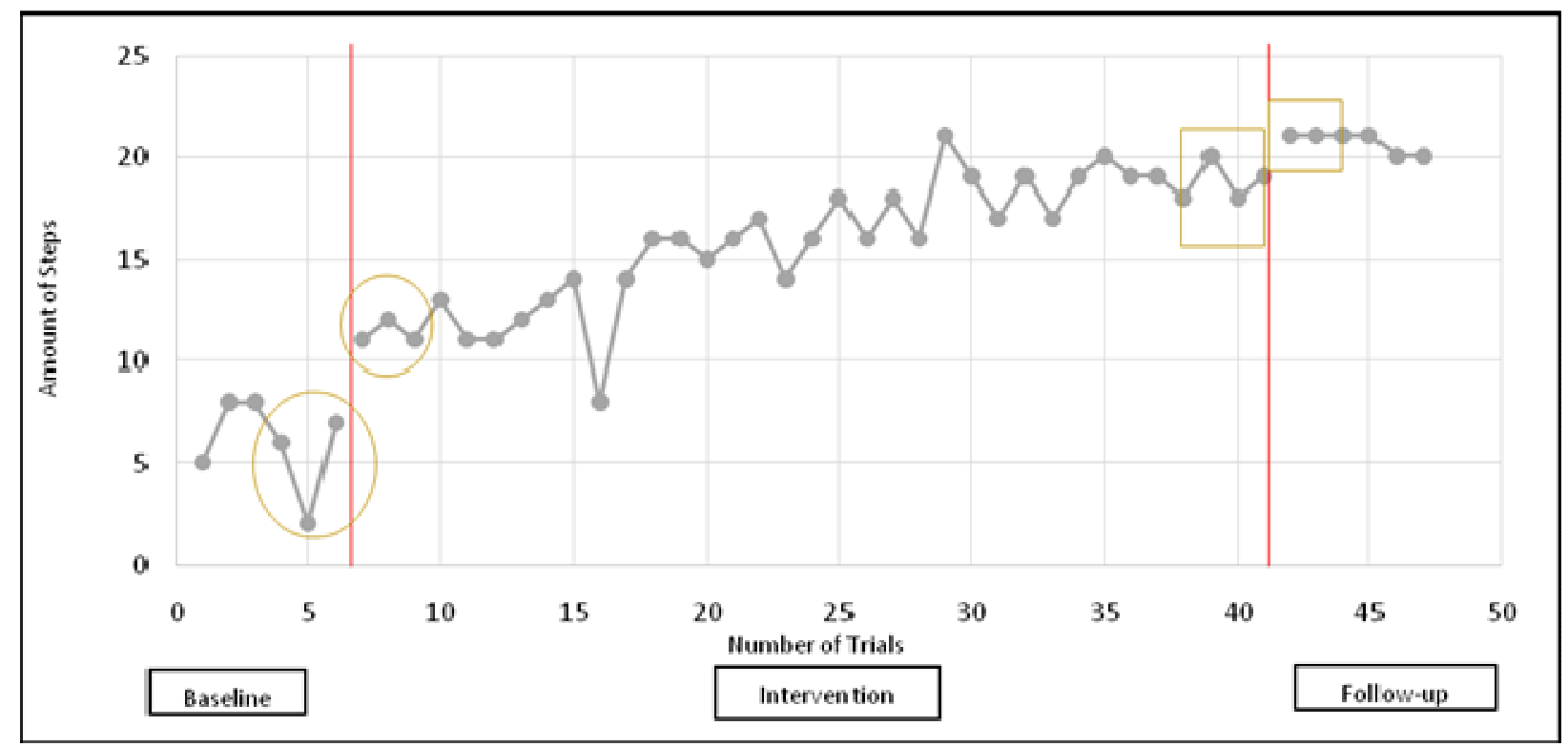

Figure 3. Immediacy of Effect Between Phases

Figure 4 depicts the overlap feature. Based on Figure 4, one data overlap existed in the baseline and intervention phases, and another overlap developed in the intervention and follow-up phases. 
The minimal overlap between phases strengthens the strong effect of intervention to the mastery of self-drinking behavior in $\mathrm{R}$.

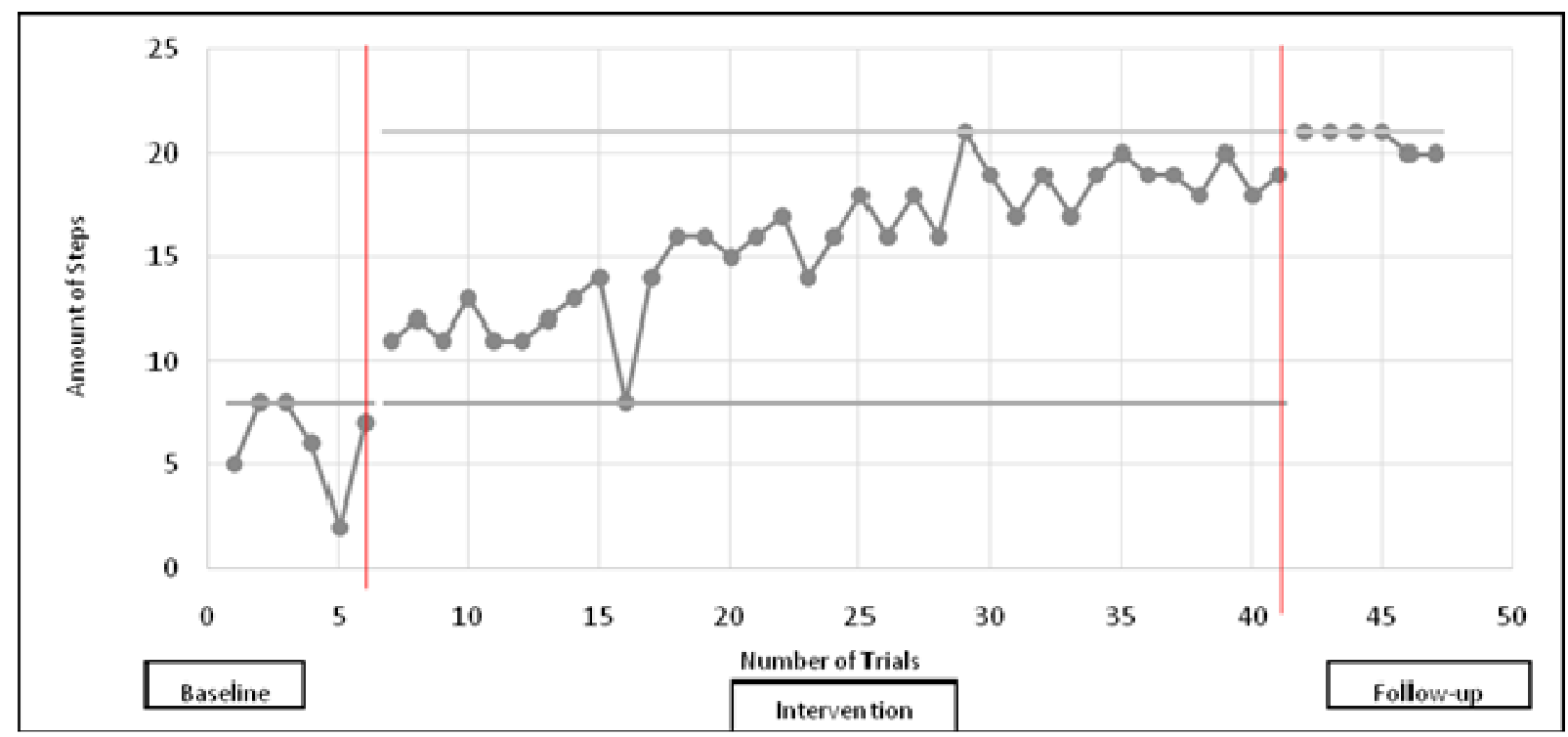

Figure 4. Overlap Between Phases

\section{Discussion}

Results showed that the use of total-task presentation technique in this behavior modification program can improve the self-drinking skill of a 9-year-2-month-old child with ASD with intellectual impairment (requiring substantial support for communication and for repetitive and restricted interest). After the intervention, $\mathrm{R}$ can independently perform all the steps on the chain of behavior. Findings of previous studies stated that total-task presentation technique is effective for teaching academic and self-help skills to children with intellectual disability (Jameson, et.al, 2012; Spooner, 1984). This study extends the previous finding by revealing the effectiveness of total-task presentation technique for teaching complex behavior related to self-help skills of children with ASD with intellectual impairment. Although total-task presentation technique is more appropriate for teaching a simple behavior (Miltenberger, 2012), in this current study, the method was effective for teaching a complex behavior (self-drinking skill). As the subject in current study has performed several steps of self-drinking skill before joining the program, the subject was more easily guided through the entire chain of behavior.

The current study features several limitations that require attention. The first limitation is the lack of inter-observer agreement. The role of examiner, program developer, and observer was played by one person without the assistance of another party in observing every session. The presence of an observer without background information of the participant will help minimize biases. Another limitation is the lack of visual recording throughout the program. The lack of recordings disables the option of reviewing each session multiple times to minimize the possibility of committing errors in data collection. Further studies should obtain visual recordings and implement the inter-observer agreement procedure to eliminate bias potentials. 
The third limitation is the lack of generalization phase across settings. Therefore, whether the participant can apply the skill he has learned in other settings cannot be determined. Lastly, task analysis is highly specific and only applies to the participant's home setting. This condition will present difficulty in replicating task analysis to teach self-drinking skill in other settings or to a larger population.

Despite these limitations, results of the current study can inspire the adoption of total-task presentation technique in self-help teaching programs for intervention programs targeting children with ASD with intellectual impairment. Notably, the children must already be adept in some steps of the target behavior or skill and must exhibit familiarity to the behavior.

\section{References}

Anderson, S. R., Jablonski, A. L., Thomeer, M. L., \& Knapp, V. M. (2007). Self-help skills for people with autism: A systematic teaching approach. Bethesda: Woodbine House, Inc.

Carruth, B. R., \& Skinner, J. D. (2002). Feeding behaviors and other motor development in healthy children (2-24 months). Journal of the American College of Nutrition, 21(2), 88-96. doi: 10.1080/07315724.2002.10719199

Flynn, L., \& Healy, O. (2012). A review of treatments for deficits in social skills and self-help skills in autism spectrum disorder. Research in Autism Spectrum Disorders, 6(1), 431-441. doi: 10.1016/j.rasd.2011.06.016

Jameson, J. M., Walker, R., Utley, K., \& Maughan, R. (2012). A comparison of embedded total task instruction in teaching behavioral chains to massed one-on-one instruction for students with intellectual disabilities: Accessing general education settings and core academic content. Behavior modification, 36(3), 320-340. doi: 10.1177/0145445512440574

Kratochwill, T. R., Hitchcock, J., Horner, R. H., Levin, J. R., Odom, S. L., Rindskopf, D. M \& Shadish, W. R. (2010). Singlecase designs technical documentation. Retrieved from http://ies.ed.gov/ncee/wwc/pdf/wwc_scd.pdf.

Martin. G. \& Pear, J. (2015). Behaviour modification: What it is and how to do it $\left(10^{\text {th }}\right.$ Ed.). USA: Pearson Education

Perry, A., Flanagan, H. E., Geier, J. D., \& Freeman, N. L. (2009). Brief report: The Vineland Adaptive Behavior Scales in young children with autism spectrum disorders at different cognitive levels. Journal of autism and developmental disorders, 39(7), 1066-1078. doi: 10.1007/s10803-009-0704-9

Spooner, F. (1984). Comparisons of backward chaining and total task presentation in training severely handicapped persons. Education and Training of the Mentally Retarded, 19(1), 15-22.

Thurm, A., Lord, C., Lee, L. C., \& Newschaffer, C. (2007). Predictors of language acquisition in preschool children with autism spectrum disorders. Journal of autism and developmental disorders, 37(9), 1721-1734. doi: 0.1007/s10803-006-0300-1

Vivanti, G., Barbaro, J., Hudry, K., Dissanayake, C., \& Prior, M. (2013). Intellectual development in autism spectrum disorders: new insights from longitudinal studies. Frontiers in Human Neuroscience, 7. doi: 10.3389/fnhum.2013.00354

Wong, C., Odom, S. L., Hume, K. A., Cox, A. W., Fettig, A., Kucharczyk, S.,... \& Schultz, T. R. (2015). Evidence-based practices for children, youth, and young adults with autism spectrum disorder: A comprehensive review. Journal of Autism and Developmental Disorders, 45(7), 1951-1966. doi: 10.1007/s10803-014-2351 
